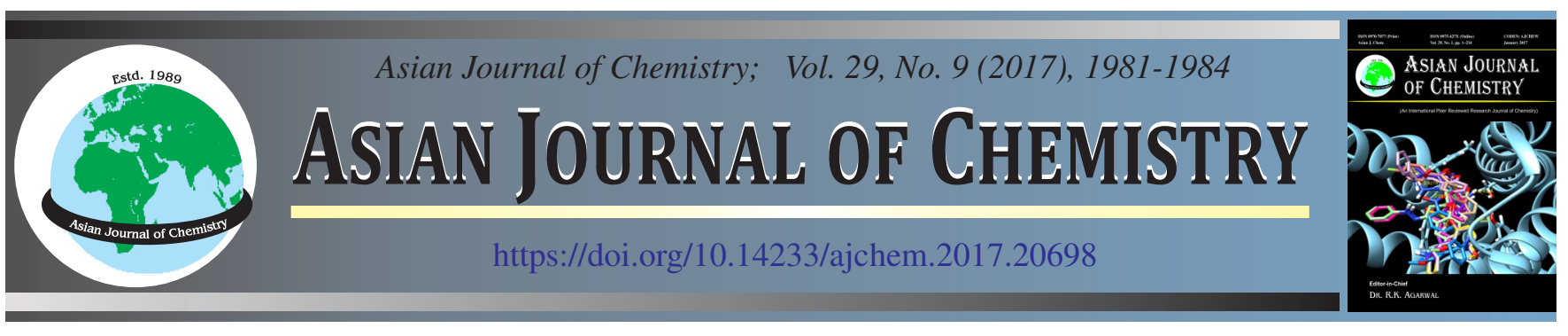

\title{
Effects of Milling Parameters on Rheological Behaviours of Silica Nanofluid Prepared by Two-Step Process
}

\author{
DeEPaK Davis, JiL Joy and SheEla Singh*
}

Department of Physics and Nano Technology, Faculty of Science and Humanities, SRM University, Kattankulathur, Chennai-603 203, India *Corresponding author: E-mail: sheela2k5@gmail.com

\begin{abstract}
Nanofluids have garnered the attention of material science and heat transfer fraternity across the world for the reported enhancement of their thermal properties and the amenability for a change of their rheological properties under external influence. Of the various nanofluids that have been studied widely, nano-silica fluids comprise a predominant fraction. The alterations in the morphological characteristics of the nano-silica fluids brought about by mechanical treatment of the samples influence their chemical and rheological behaviours. The present work involves the study of milling parameters on the rheological behaviours of silica particles. The micron size silica is reduced to nano size by ball milling, done by $0-20 \mathrm{~h}$ at $300 \mathrm{rpm}$ in Fritsch P5 planetary ball mill. This milled powder will be characterized by XRD and SEM for it crystallite size and morphology. Thus prepared silica on treatment with ethylene glycol and water mixture enhances its dispersion in fluids.
\end{abstract}

Keywords: Silica nanofluid, Rheological properties, Ball milling, Two-step process.

\section{INTRODUCTION}

Nanofluidics is a new class of fluid engineered by the dispersion of high purity of nano-sized material into the base fluid. Also, known that the nano-size colloidal suspension contains condensed nano-size material. Nanofluids are two phase system with one phase of the solid phase and in another liquid phase. It is found to enhance the thermal and physical properties like thermal conductivity, thermal diffusion, viscosity and conductive heat transfer coefficient compared to those of base fluids like water or engine oil. It has huge potential application in the automobile industry, electronic industry and other fields. The two-phase system, few issues should face in day to day life. To achieve desired stability of nanofluid remains a big challenge. Preparation of method of nanofluid mainly classified into different methods like two step method, one step method and another novel method. In two-step method, nano-size powder first produced as a dry powder and then it will be dispersed into base fluid in the second step with help of proper dispersion method. It is a most economic method to produce nanofluid in large industry scale. Some cases surfactants were used to enhance the stability [1-6].

Eastman et al. [7] developed a one step physical vapour condensation method for the one-step method. In this method, consist of simultaneously making and dispersing the particles in the fluid and it is avoiding the process of drying, storage and transportation. This will be lead to a reduction of agglomeration and increase the stability. Due to the stability problem, researchers developing a new novel method to produce nanofluids. Wei and Wang [8] developed a continuous flow of microfluidic-microreactor to synthesize copper nanofluids. In this method, copper nanofluids will be continuously synthesized and their microstructure and properties can be varied by adjusting parameters like reactant concentration, flow rate and additive, temperature, acidity $(\mathrm{pH})$, ultrasonic and microwave irradiation, types and concentrations of reactants. One-step chemical solution method (CSM) has been recently developed for creating nanofluids, which have the capable of synthesizing nanofluids of various microstructures. The nanofluids produced by the chemical solution method have both enhancement of higher conductivity and higher stability than those produced by the other methods [9-12].

One of the main problems of the one-step method is can't able to produce in large scale and cost of production is high. The stability is a key issue that influences the properties of nanofluids for application and it is necessary to study the influencing factors of nanofluids. The stability evaluation methods, different ways to enhance the stability and the stability mechanisms are the different parameters. The present work involves the study of milling parameters on the rheological behaviours of silica particles. 


\section{EXPERIMENTAL}

For the preparation of the nanofluid, two-step methods were using. Micron size silica particle was synthesized following by the mechanical alloying route. It allows the production of a homogenous dispersion of nanopowder. The initial process of mechanical alloying is starting with the right proportion of silica powder and loading the powder sample along with grinding ball in high energy ball mill. The initial precursor is $\mathrm{SiO}_{2}$ micron size powder with 140 mesh size (99.05\% purity) were mechanical alloying at normal room temperature. Using high energy Fritsch P5 Planetary Ball Mill with WC grinding medium at $300 \mathrm{rpm}$ and 1:10 powder to ball ratio were using. The milling was carried out at in wet medium like toluene, for the desired period of time like 5, 10, 15 and $20 \mathrm{~h}$. After the grinding, the powder will dry in natural room temperature. The prepared powder will be characterized by X-ray diffraction (XRD), field emission scanning electron microscope (FESEM) and energy dispersive spectroscopy (EDS) to identify the phase, particle/crystallite size, shape/morphology and purity.

Mechanical alloying based dried silica powder will be dispersed into the fluid in the second processing step with the help of magnetic force and ultrasonic agitation. Up to 1 vol. \% of dry powder of $\mathrm{SiO}_{2}$ will be dispersed in ethylene glycol and deionized water mixture, by the help of ultrasonic bath and magnetic stirring for effective dispersion into ethylene glycol mixture. The prepared nano silica fluid will be characterized by zeta potential analyzer.

\section{RESULTS AND DISCUSSION}

The ultrasonication processing time was set for $30 \mathrm{~min}$ for preparing for nanofluid and magnetic stirring was carried out for $60 \mathrm{~min}$. X-ray diffractometer (X-pert Pro, Panalytical) was used to investigate the phase of material and obtained as amorphous state silica. The analysis was performed using a $\mathrm{Cu}$ target (voltage and current of $40 \mathrm{kV}$ and $20 \mathrm{~mA}$, respectively), with a scan range of 0 to $100^{\circ}$ and speed of $1^{\circ}$ for a minute. The XRD intensity shows that the grinding hours increasing with intensity (Fig. 1). The XRD pattern of $\mathrm{SiO}_{2}$ shows a strong peak at $2 \theta=23.68^{\circ}$ attributed to the (002) crystalline plane (Fig. 1).

Fig. 2 shows the different milling time intervals image of field emission scanning electron microscope (FESEM - CARL ZEISS, Supra 40VP, 2009). It indicates that particle size is reducing by increasing the milling time also the agglomeration chances are getting increasing. The EDAX analysis is confirmed the higher purity of $\mathrm{SiO}_{2}$ because of the absences of other material (Fig. 3).

Coolants with higher thermal characteristics than water need to be applied for better cooling. Nanofluid is a potential coolant for heat transfer application such as fuel cell thermal management and electronic device cooling and automobile sector [13]. The presence of nanoparticles in the base fluid increase the thermal conductivity behaviour. It is an important property in heat transfer. However, nanofluid also shows higher viscosity and electrical conductivity as the particle concentration is increased across temperature. High viscosity correlated to the pressure drop and pumping power.

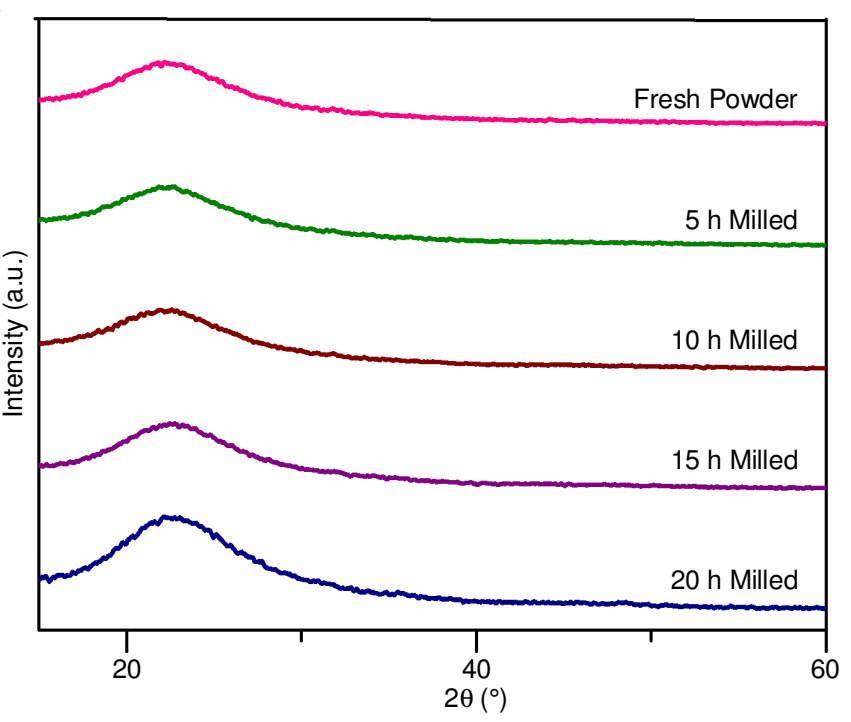

Fig. 1. XRD image of $\mathrm{SiO}_{2}$ micro/nanopowder as synthesized at different time intervals $(2 \theta=23.68$ attributed to $(002)$ crystalline plane)

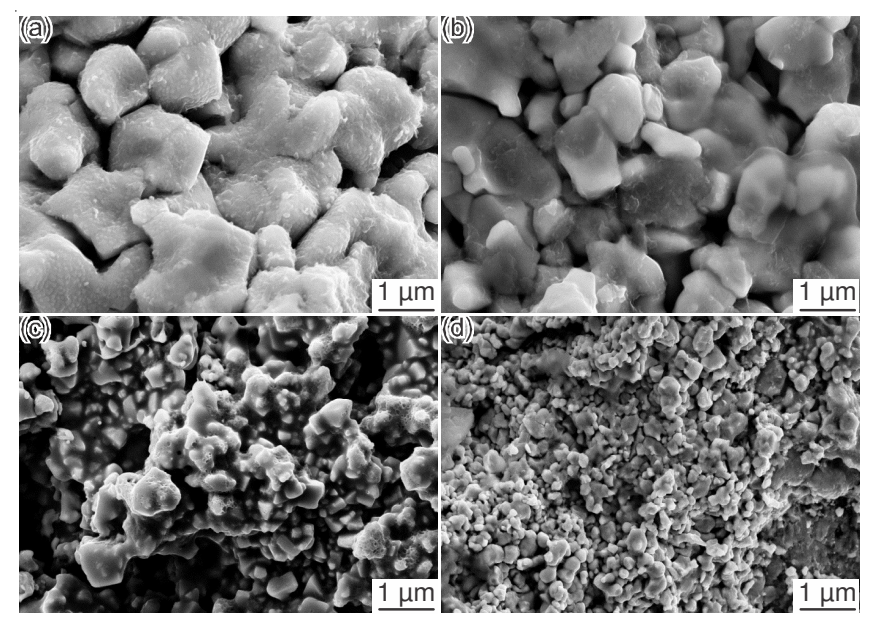

Fig. 2. FESEM image of $\mathrm{SiO}_{2}$ nano/micro powder after different milling time intervals, A: 5 h, B: 10 h, C: 15 h, D: $20 \mathrm{~h}$

\begin{tabular}{|c|c|c|c|c|c|c|c|}
\hline El & AN & Series & $\begin{array}{l}\text { unn. c } \\
\text { [wt \%] }\end{array}$ & $\begin{array}{c}\text { norm. C } \\
{[\text { wt \%] }}\end{array}$ & $\begin{array}{c}\text { Atom. C } \\
\text { [at \%] }\end{array}$ & Error & $\begin{array}{c}\text { (1 Sigma) } \\
\text { [wt \%] }\end{array}$ \\
\hline 0 & 8 & K-series & 45.69 & 64.38 & 76.04 & & 8.42 \\
\hline Si & 14 & K-series & 25.28 & 35.62 & 23.96 & & 1.22 \\
\hline
\end{tabular}

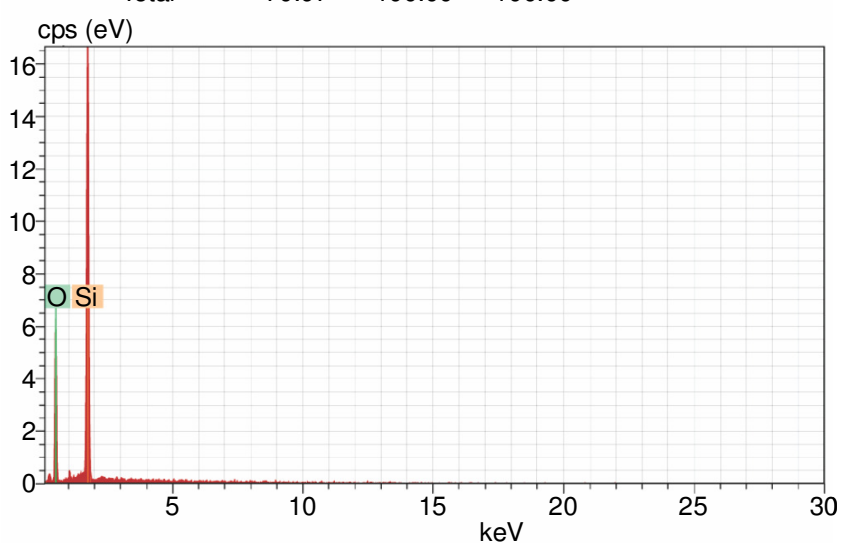

Fig. 3. EDAX image of prepared $\mathrm{SiO}_{2}$ micron/nano size powder 


\section{TABLE-1}

PROPERTIES OF NANOPARTICLES AND BASE FLUIDS

\begin{tabular}{lccccc}
\hline $\begin{array}{c}\text { Nanoparticle/base } \\
\text { fluid }\end{array}$ & $\begin{array}{c}\text { Thermal conductivity } \\
(\mathrm{k})(\mathrm{W} / \mathrm{m} \mathrm{K})\end{array}$ & $\begin{array}{c}\text { Electrical conductivity } \\
(\sigma)(\mu \mathrm{S} / \mathrm{cm})\end{array}$ & $\begin{array}{c}\text { Dielectric } \\
\text { constant }(\varepsilon)\end{array}$ & $\begin{array}{c}\text { Density }(\rho) \\
\left(\mathrm{kg} / \mathrm{m}^{3}\right)\end{array}$ & Reference \\
\hline $\mathrm{SiO}_{2}$ & 1.380 & 10.00 & 3.9 & 2220 & {$[14]$} \\
Distilled water & 0.615 & 6.00 & 80.0 & 999 & {$[15]$} \\
Ethylene glycol & 0.252 & 1.07 & 38.0 & 1110 & {$[16]$} \\
\hline
\end{tabular}

Among all prepared 4 different set of silica nanofluids, $20 \mathrm{~h}$ milled $\mathrm{SiO}_{2}$ nanofluid shows less particle size [Fig. 5(b)]. Based on the results, if the particle size is reduced the effective thermal conductivity will increase so that further characterization were carried out in $20 \mathrm{~h}$ milled $\mathrm{SiO}_{2}$ nanofluid.

Properties of nanoparticle and base fluid used in the experiment listed in Table-1. The thermal conductivity, electrical conductivity and viscosity are measured at room temperature. The thermal conductivity, viscosity and electrical conductivity are measured using KD2Pro Thermal Analyzer, Zetasizer Nano ZS (Malvern Instruments Ltd., UK), Brookfield DVIII Ultra Programmable Rheometer and Cyberscan PC-10, respectively. The effective thermal conductivity of ethylene glycol and water mixture is shown to be increased up to $30 \%$ by the addition of a nanofluid consisting of approximately 0.35 volume $\% \mathrm{SiO}_{2}$ nanoparticles of mean diameter $78 \mathrm{~nm}$.

First, significant increases in thermal conductivity are seen for $\mathrm{SiO}_{2}$ nanofluids, with conductivity enhancements of up to $30 \%$ observed for particle loadings well up to one volume percent compared to fresh ethylene glycol and deionized water mixture fluid with nanoparticle addition (Fig. 4). As compared with fluids containing $\mathrm{SiO}_{2}$ nanoparticle without particles, showed there is an improvement in thermal conductivity.

The sample was milled for $2 \mathrm{~h}$ in ethylene glycol and deionized water mixture nanofluid will further characterize because of the thermal conductivity improvement. The milling time is increasing, with respect to the increasing absorption

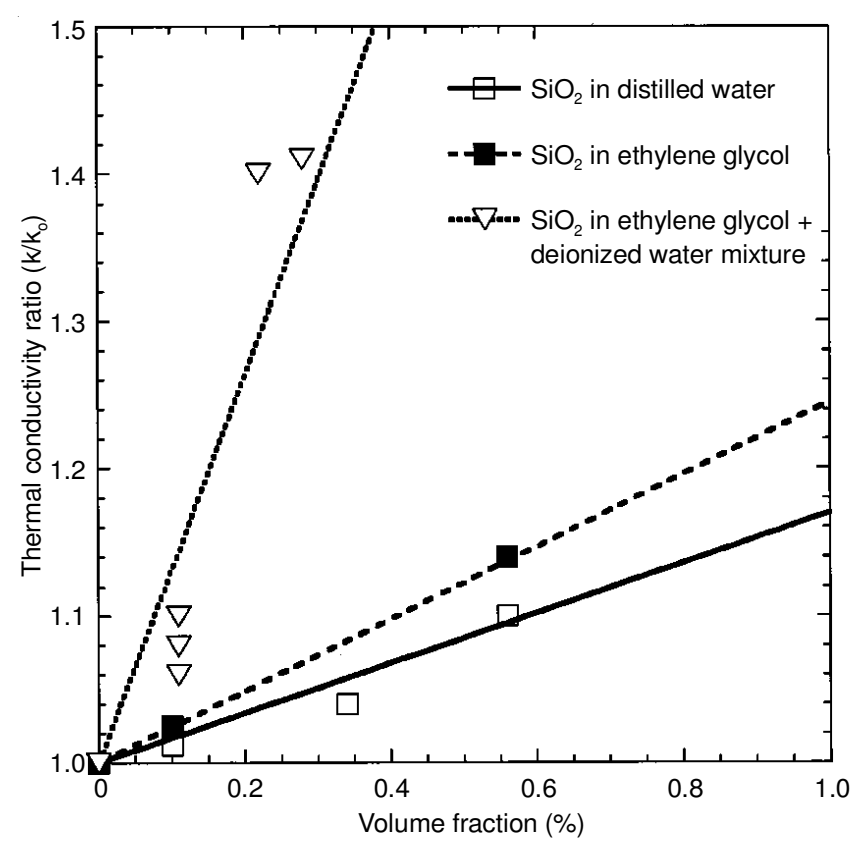

Fig. 4. Thermal conductivity of prepared $\mathrm{SiO}_{2}$ nano particle in different medium

[Fig. 5(a)]. Milling time vs. particle size distribution shows the milling time increases with decreasing of the particle size distribution [Fig. 5(b)]. It was determined by using a Zetasizer Nano ZS (Malvern Instruments Ltd., UK). The viscosity of
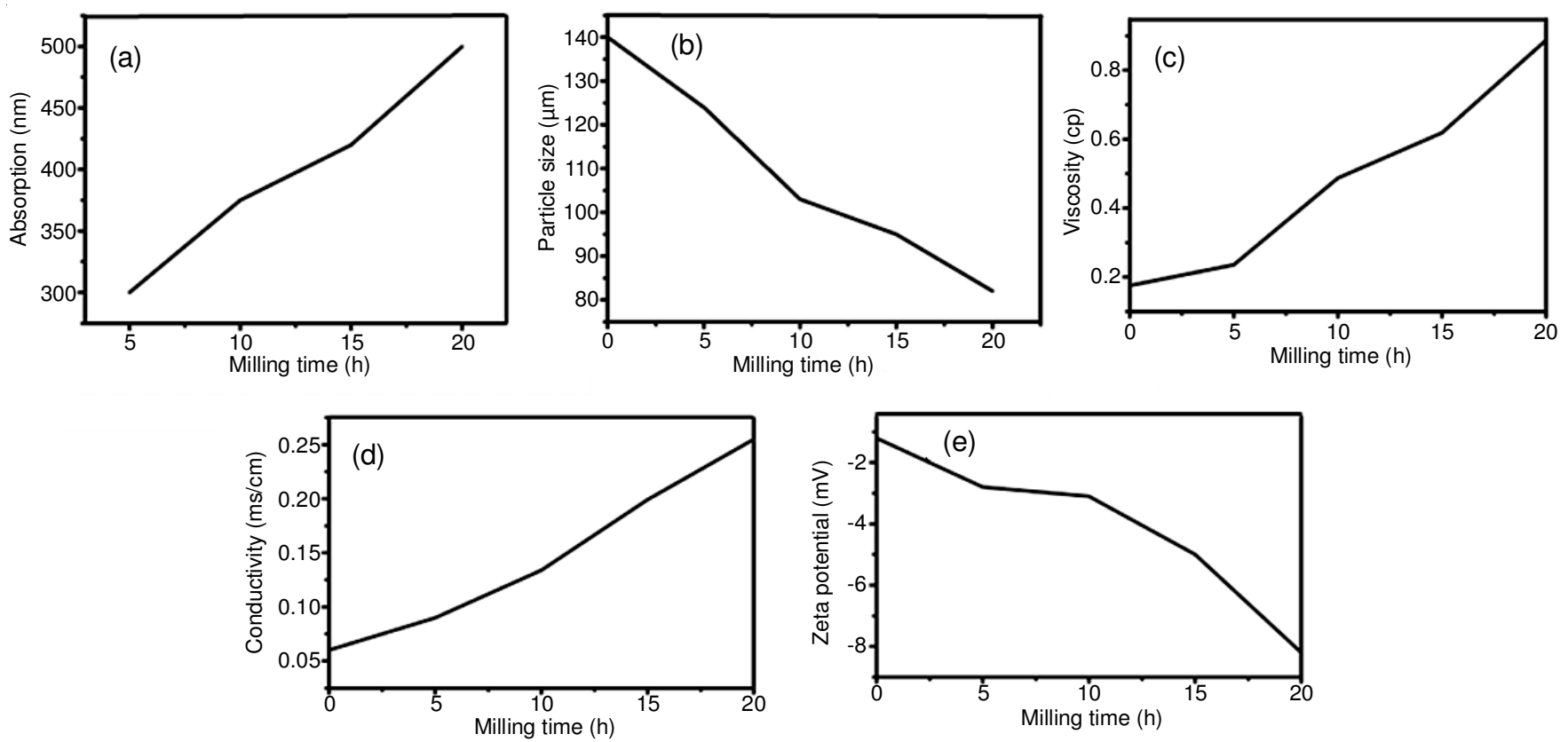

Fig. 5. (a) Milling hours $v s$. absorption (nm) of prepared of prepared $\mathrm{SiO}_{2}$ micro/nanofluid; (b) Milling hours vs. particle size distribution $\mathrm{SiO}_{2}$ micro/nanopowder; (c) Milling hours $v s$. viscosity of prepare $\mathrm{SiO}_{2}$ micro/nanofluid; (d) Milling hours $v s$. conductivity of prepared $\mathrm{SiO}_{2}$ micro/nanofluid; (e) Milling hours vs. zeta potential of prepared $\mathrm{SiO}_{2}$ micro/nanofluid 
the nanofluid is increasing within increasing milling time, for $20 \mathrm{~h}$ milled nanofluid samples viscosity is getting maximum of $0.8875 \mathrm{cp}$ [Fig. 5(c)]. If the temperature increases simultaneously, the viscosity decreases. Zeta potential and conductivity showing the same trend like increasing milling time with increasing conductivity and zeta potential [Fig. 5(d,e)], for $20 \mathrm{~h}$ nanofluid sample shows the conductivity of $0.255 \mathrm{~ms} / \mathrm{cm}$ and zeta potential of $-7.65 \mathrm{mv}$, respectively.

\section{Conclusion}

In summary, the $20 \mathrm{~h}$ milled silica dispersed ethylene glycol mixed deionized water nanofluid shows better rheological behaviours compared to other samples. Better significant increases in thermal conductivity are seen for $\mathrm{SiO}_{2}$ nanofluids, with conductivity enhancements of up to $30 \%$ observed for particle loadings well up to one volume percent. As compared with fluids containing $\mathrm{SiO}_{2}$ nanoparticle without particles, showed there is an improvement in thermal conductivity in the case of $\mathrm{SiO}_{2}$ nanoparticle addition. The prescribed protocol is very economical compared to the protocol for preparing nano-fluid in large scale. The rheological behaviours strongly depending upon the process parameters like size shape of the particle, viscosity, conductivity and also the nature of dispersion medium. High viscosity shows more chances of aggregations.

\section{ACKNOWLEDGEMENTS}

The authors acknowledge to Department of Physics and Nanotechnology, SRM University, Kattankulathur, Chennai, India for providing the research facilities.

\section{REFERENCES}

1. S.U.S. Choi, Z.G. Zhang and P. Keblinski, ed.: H. S. Nalwa, Nanofluids, In: Encyclopedia of Nanoscience and Nanotechnology, American Scientific Publishers, New York, pp. 757-773 (2004).
2. S.K. Das, S.U.S. Choi, W.H. Yu and T. Pradeep, Nanofluids: Science and Technology, Wiley-InterScience, New Jersey (2007).

3. G.P. Peterson and C.H. Li, Adv. Heat Transf., 39, 257 (2006); https://doi.org/10.1016/S0065-2717(06)39003-X.

4. D.X. Wu, H.T. Zhu, L.Q. Wang and L.M. Liu, Curr. Nanosci., 5, 103 (2009); https://doi.org/10.2174/157341309787314548.

5. J.A. Eastman, S.R. Phillpot, S.U.S. Choi and P. Keblinski, Ann. Rev. Mater. Res., 34, 219 (2004); https://doi.org/10.1146/annurev.matsci.34.052803.090621.

6. C.H. Lo, T.T. Tsung and L.C. Chen, J. Cryst. Growth, 277, 636 (2005); https://doi.org/10.1016/j.jcrysgro.2005.01.067.

7. J.A. Eastman, S.U.S. Choi, S. Li, W. Yu and L.J. Thompson, Appl. Phys. Lett., 78, 718 (2001);

https://doi.org/10.1063/1.1341218.

8. X. Wei and L. Wang, Particuology, 8, 262 (2010); https://doi.org/10.1016/j.partic.2010.03.001.

9. L.Q. Wang and M. Quintard, eds.: in L.Q. Wang, Nanofluids of the future, In: Advances in Transport Phenomena, Springer- Verlag, Heidelberg, pp. 179-243 (2009).

10. L.Q. Wang and X.H. Wei, J. Heat Transfer, 131, 033102 (2009); https://doi.org/10.1115/1.3056597.

11. X.H. Wei, H.T. Zhu, T.T. Kong and L.Q. Wang, Int. J. Heat Mass Transfer, 52, 4371 (2009); https://doi.org/10.1016/j.ijheatmasstransfer.2009.03.073.

12. X.H. Wei, H.T. Zhu and L.Q. Wang, J. Thermophys. Heat Transfer, 23, 219 (2009); https://doi.org/10.2514/1.38778.

13. A. Ijam and R. Saidur, Appl. Therm. Eng., 32, 76 (2012); https://doi.org/10.1016/j.applthermaleng.2011.08.032.

14. S. Zhang and N. Ali, Nanocomposite Thin Films and Coatings-Processing, Properties and Performance, World Scientific (2007).

15. 2012 ASHRAE Handbook-Heating, Ventilating and Air-Conditioning Systems and Equipment (SI Edition), In: Combined Heat and Power System, American Society of Heating, Refrigerating and Air-Conditioning Engineers, Inc. (2012).

16. S.F.A. Talib, W.H. Azmi, I. Zakaria, W. Mohamed, A.M.I. Mamat, H. Ismail and W.R.W. Daud, Energy Procedia, 79, 366 (2015); https://doi.org/10.1016/j.egypro.2015.11.504. 